
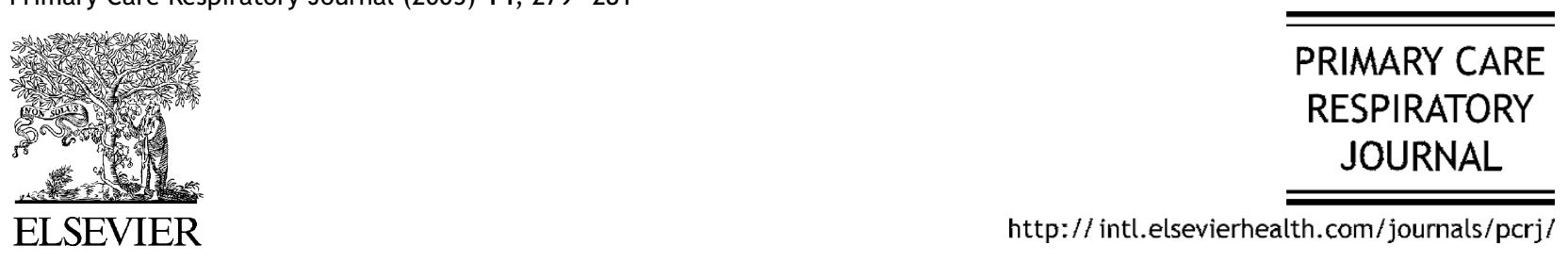

\title{
Changes to the home oxygen provision service in the UK
}

The United Kingdom (UK) Department of Health made an announcement during 2003 concerning its plans to modernise the National Health Service (NHS) home oxygen service [1]. The following year the NHS Purchasing and Supply Agency invited tenders for a new contract to deliver an integrated home oxygen service. This five-year contract includes the provision of concentrator, cylinder and ambulatory oxygen, and the service provider will be required to deliver the service as set out in $\bar{u}$ detailed specification. A wide range in aikehbiders were consulted, incluoirg clinical staff, patient representatives, (1):-imary Care Tinust: (PC)-Che current term for Primary Care Organisations in the UK), the NHS Purchasing and Supply Agency (PASA), the Medicines and Healthcare Products Regulatory Agency (MHRA) and potential service providers. These new arrangements are planned to come into force on February 1st 2006, but despite the wide range of consultation with stakeholders many healthcare professionals in the UK are unaware of these impending changes to home oxygen service provision.

In 1999, a Royal College of Physicians (RCP) working group made a number of recommendations on the assessment of oxygen needs [2]. The UK Department of Health followed this up with its own review of the home oxygen service. Both reports concluded that there was a need to improve the clinical effectiveness of the service and that this should include the provision of ambulatory oxygen. Currently, choice of equipment available on NHS prescription is restricted. General practitioners (GPs) prescribe home oxygen therapy on a standard UK 'FP10' NHS prescription form. Retail pharmacies, and some dispensing doctors, provide a cylinder service to patients, and they order cylinder oxygen for patients under an agreement with a medical gas supplier. The current oxygen concentrator service provision was set up 20 years ago with three comperies providing a service in "nine res ens Covering England and Wa ô. 10wevel, significant advances in technology chave improved sefety standards and have provided the aboityllolbifer more choice in meeting Opatints oxygen needs. GPs have also expressed concerns about choosing oxygen equipment when they have little technical knowledge to support their decision-making. The Department of Health's review concluded that better use should be made of the technical expertise and experience of oxygen equipment suppliers who should have greater freedom to make decisions on equipment that best meets specific oxygen requirements.

From February 1st 2006 the new UK arrangements will identify ten new oxygen service regions covering England (the National Assembly for Wales has assumed responsibility for healthcare services in Wales), each region generally matching Strategic Health Authority boundaries. An integrated, single supply route, with servicing for concentrator, cylinder and ambulatory oxygen will be provided by a single contractor in each of the ten oxygen service regions on a 24 hours a day/7 days a week basis. Each region had a local evaluation team who nominated three preferred providers based on business case and presentation, and the Department of Health then selected 
different providers from each region's preferred list to ensure that there was not a monopoly situation.

Specialist staff, as well as GPs, will be able to order home oxygen direct from the provider using an oxygen order form. FP10 prescribing will no longer be required and prescriptions to local pharmacists will not be dispensed after February 1st 2006. The oxygen order form provides the service contractor with information on a patient's clinical needs (ie oxygen flow rate and hours of use). There is also space on the form for clinical staff to provide any additional information that they feel the contractor needs when providing oxygen equipment and training for a patient - for example, a child using a cot or pushchair, or an adult with visual impairment. Clinical staff will not need to specify equipment - however, they will be able to express a preference based on clinical assessment. They will order an oxygen service (eg emergency, short-burst, long-term oxygen therapy (LTOT), or ambulatory service), specifying the oxygen flow rate for the patient and the required hours of use. Use of this oxygen order form should also provide policy makers with data upon which to commission future services.

The service provider/contractor's role is to use their technical expertise and the clirica! information provided by the specialist $i \in a$ or or $G P$ to decide upon the equininent tinatbest meets the needs of pracieries. Liscession may need tol take place between the provider an tinical ceam. The supplier is required to provide the service within a specified response time: within one to three days as required; an emergency, four-hour response if needed with supply for a maximum of three days duration; or an out-of-hours service. Caution and appropriate prescribing should be used for the emergency oxygen service since this carries a cost premium. It may well be the clinical team's responsibility to discontinue the emergency oxygen service when appropriate. This service is likely to be used for palliative care only and should not be used as a 'short cut' to achieve a speedy service.

Staff may fax or e-mail the oxygen order form to the supplier who is required to confirm receipt within 24 hours. A copy of the order form should be sent to the PCT as part of contract management arrangements. The clinical team and the PCT will have access to a computer site to monitor the provision of oxygen and patient usage, and in the future a paperless system will be introduced.

Home oxygen service funding, irrespective of the source of the original prescription, will be wholly transferred to PCT unified budgets (ie across primary and secondary care) as opposed to the cost being borne solely by primary care. These budgets will be based 50\% against a capitation formula and $50 \%$ on historical spend. The exact procedures will be finalised locally between the provider and the PCT. The new service will allow a standardised approach to payment (five funding routes streamlined to one), with improved patient and performance management information to support PCT management of contracts. The service provider is required to meet the standards set out in the five-year contract and this includes a clear, detailed, specification for the service. Currently there is no service specification for the provision of the oxygen cylinder service.

Clinical best practice guidelines recommend specialist assessment of patients requiring long-term oxygen therapy (LTOT) or ambulatory oxygen [3.4]. Local specialist assessment and review services should therefore be developed to ensure appropriate and effective use of the oxygen service. The service contractor will continue to provide the service ordered by specialist staff until receipt of a revised order or notification to withdraw the service.

These clinical guidelines [34] jidentify three oxygen therapy services:

Iorig-terin bxygen therapy (LTOT), for patients heeding oxygeh forct least 15 hours a day, including at night, and ior continuous use in the patient's home. GPs or specialists may order LTOT, but it is recommended that GPs refer their patients for specialist assessment where there are complex or long-standing oxygen needs.

Ambulatory oxygen: Most patients on LTOT who are mobile and are able to or need to leave home, require assessment for ambulatory oxygen therapy. The BTS clinical best practice guidelines [3] recommend specialist assessment of ambulatory oxygen needs since not all LTOT patients will benefit from this service. Therefore, specialist teams are likely to order ambulatory oxygen therapy after an assessment of benefit/improved exercise tolerance on oxygen.

Short burst oxygen therapy (SBOT): Clinicians order SBOT for the alleviation of intermittent breathlessness in those patients not requiring LTOT or ambulatory oxygen. Clinical guidelines recommend a review of these patients' needs after one year, including any continuing need for oxygen therapy. Both GPs and specialist staff may order SBOT for their patients. For example, a GP may order SBOT whilst his/her patient is awaiting specialist assessment for LTOT and/or ambulatory oxygen, and the specialist team may order SBOT on 
hospital discharge where a patient is not yet well enough or clinically in a stable state to undertake assessment for LTOT or ambulatory oxygen.

The British Thoracic Society [4] and the National Institute for Clinical Excellence [5] guidelines on managing patients with chronic obstructive pulmonary disease (COPD) highlight the need for effective clinical assessment and review services for those patients receiving home oxygen therapy. The guidelines include oxygen therapy as an important element in managing the care of COPD patients. The estimated 600,000 diagnosed COPD patients in the UK are amongst the most frequent users of primary and secondary care services but it is worth remembering that they will not be the only patient group that can benefit from home oxygen therapy.

The new system for provision of home oxygen to patients should mean more choice for patients, with improved access to portable and ambulatory oxygen including liquid oxygen. However, it is important that pharmacies and dispensing doctors are able to continue to provide a cylinder service until the contractors take on the new integrated home oxygen contract. Currently, the main concern is the potential lack of oxygen cylinder headsets provided by pharmacists. The new providers will be using cylinders with integrated headsets and there are no plans at present to reimburse pharnecisis who purchase the old-stvlenteads=tr for loan to patients. PCTs have beengyiven the responsibil: ty to provide the necessary headscsenthe interim $[6,7]$. It has been proposed that patients using cylinders on a regular basis should be switched to concentrators for the transition period. Clinically this may be an unsatisfactory arrangement but it may be better than leaving a patient without oxygen.

The introduction of this new home oxygen provision service in the UK requires careful management by all concerned to ensure that patients continue to receive the service they need, thereby avoiding undue pressures on emergency and out-of-hours services and the admission of patients to hospital due to gaps in maintaining home oxygen services. There is a real need to raise awareness of these changes amongst all health professionals, including hospital medical teams, GPs, community nurses, Macmillan nurses, out-of-hours services, and hospice staff. It is important to note that some of the current oxygen provision services may change before implementation of these new arrangements in February 2006.

\section{References}

[1] http://www.dh.gov.uk.

[2] Rudolf M, Wedzicha W, Calverley $P$, et al. Domiciliary oxygen therapy services. Clinical Guidelines and advice for prescribers. A report of the Royal College of Physicians. 1999. London, Royal College of Physicians. ISBN 1860160816.

[3] Clinical Component For The Home Oxygen Service In England And Wales, Update December 2004. http: //www. brit-thoracic.org.uk.

[4] Chronic Obstructive Pulmonary Disease: National clinical guideline for management of chronic obstructive pulmonary disease in adults in primary and secondary care. Thorax 2004;59(suppl 1): 1-23?.

[5] Chronir Olstilctive Cul nonary Disease: National clinical ǵlideline for manajement of chronic obstructive pulmonary cliceásein adults in primary and secondary care. (1'it cral Eentre For Clinical Excellence. NICE: h tis!/iwww.nice.org.uk. 2000.

[6] http://www.psnc.org.uk.

[7] http://www.primarycarecontracting.nhs.uk.

Linda Pearce (Respiratory Nurse Consultant)* Department of Respiratory Medicine, West Suffolk Hospital, Bury St Edmunds, Suffolk IP11 9JP, UK

*Tel.: +44 (0) 1284713000 .

E-mail address: linda.pearce@wsh.nhs.uk

10 March 2005

Available online at www.sciencedirect.com

science $(\mathcal{d}$ irect 